OPEN ACCESS

Edited by:

Monica Livia Gheorghiu, Carol Davila University of Medicine and Pharmacy, Romania

Reviewed by:

Greisa Vila

Medical University of Vienna, Austria Jacqueline Trouillas, Université Claude Bernard Lyon 1,

France

*Correspondence:

Odelia Cooper

Odelia.cooper@cshs.org

Specialty section:

This article was submitted to

Pituitary Endocrinology,

a section of the journal

Frontiers in Endocrinology

Received: 14 June 2021 Accepted: 28 October 2021 Published: 15 November 2021

Citation:

Cooper O, Bonert V, Liu NA and Mamelak AN (2021) Treatment of Aggressive Pituitary Adenomas: A

Case-Based Narrative Review.

Front. Endocrinol. 12:725014. doi: $10.3389 /$ fendo.2021.725014

\section{Treatment of Aggressive Pituitary Adenomas: A Case-Based Narrative Review}

\author{
Odelia Cooper $^{1 *}$, Vivien Bonert ${ }^{1}$, Ning-Ai Liu ${ }^{1}$ and Adam N. Mamelak ${ }^{1,2}$ \\ ${ }^{1}$ Pituitary Center, Department of Medicine, Cedars-Sinai Medical Center, Los Angeles, CA, United States, ${ }^{2}$ Department of \\ Neurosurgery, Cedars-Sinai Medical Center, Los Angeles, CA, United States
}

Management of aggressive pituitary adenomas is challenging due to a paucity of rigorous evidence supporting available treatment approaches. Recent guidelines emphasize the need to maximize standard therapies as well as the use of temozolomide and radiation therapy to treat disease recurrence. However, often these adenomas continue to progress over time, necessitating the use of additional targeted therapies which also impact quality of life and long-term outcomes. In this review, we present 9 cases of aggressive pituitary adenomas to illustrate the importance of a multidisciplinary, individualized approach. The timing and rationale for surgery, radiation therapy, temozolomide, somatostatin receptor ligands, and EGFR, VEGF, and mTOR inhibitors in each case are discussed within the context of evidence-based guidelines and clarify strategies for implementing an individualized approach in the management of these difficult-to-treat-adenomas.

Keywords: pituitary adenomas, surgery, radiation therapy, temozolomide, targeted therapy, aggressive adenomas

\section{INTRODUCTION}

Pituitary adenomas are benign, slow-growing tumors that typically respond to standard surgical and medical therapies, and only $\sim 0.2 \%$ become malignant $(1,2)$. However, there is an intermediate stage, in which benign pituitary adenomas follow a more aggressive clinical course. Although they do not metastasize, these adenomas may be large and may be invasive, showing Knosp scores of 3-4 and invasion of the sphenoid sinus and other vital structures. They also may recur at early timepoints and do not respond to multiple therapies, with $>20 \%$ exhibiting persistent growth despite optimal medical, surgical, and radiotherapy (3). In these patients, escalated treatment strategies beyond standard therapies are required to control continued tumor growth and prevent tumor-associated local and/or systemic morbidities.

Overall, patients harboring aggressive adenomas require multidisciplinary focused expert care by a team dedicated to pituitary disorders (4). In this review, we present 9 cases of aggressive pituitary adenomas treated at the Cedars-Sinai Pituitary Center, a tertiary referral center with a multidisciplinary care team in line with the recommended structure for a Pituitary Tumor Center of Excellence (4). We defined aggressive adenomas as radiologically invasive adenomas with unusually rapid growth rate or clinically relevant growth despite optimal standard therapies (3). We aim to illustrate the importance of a multidisciplinary, individualized treatment approach. We discuss these cases within the context of current evidence-based guidelines, highlighting critical 
issues in determining the appropriate time to intervene and in weighing patient- and disease-specific factors that influence treatment selection.

\section{SUMMARY OF CASES}

The 9 patients with aggressive adenomas included 7 males and 2 females, ranging in age from 20 to 56 years, diagnosed with 3 silent corticotroph adenomas (SCAs) that later converted to Cushing disease (CD); with one becoming a carcinoma, $1 \mathrm{CD}$; 1 null cell carcinoma; and 4 prolactinomas, of which one progressed to a pituitary carcinoma. There were no cases of aggressive growth hormone (GH)-secreting adenomas;. Initial adenoma size ranged from 19 to $90 \mathrm{~mm}$ (Table 1). Pathologic features are described in Table 2. Of note, SF-1 immunostaining was not available (Table 1).

The 4 patients with prolactinomas were treated initially with the dopamine agonist (DA) cabergoline, and the remaining adenomas were treated initially with surgery. Recurrences were defined as growth of the residual adenoma after subtotal resection or de novo recurrence after gross total resection. One patient developed a de novo recurrence while the remainder experienced residual adenoma growth. Eight of the 9 patients had more than one recurrence: 2 had 2 recurrences, 3 had 3 recurrences, 1 had 5 recurrences, and 2 had 6 recurrences. Time to first recurrence ranged from 1 to 9 years, with 4 patients exhibiting recurrence at 1 year, 2 patients at 2 years, and 1 patient each recurring at 5 years and 9 years. Duration of disease ranged from 8 to 21 years; 2 patients are deceased.

\section{MAXIMIZING STANDARD MEDICAL THERAPY FOR FUNCTIONING ADENOMAS}

For patients with apparently aggressive functioning adenomas, standard medical therapies should be optimized to ensure that continued adenoma growth is not due to under-dosing (3). For prolactinomas, cabergoline should be administered at a dose of least $3.5 \mathrm{mg}$ a week, and PRL normalization has been reported with doses as high as $11 \mathrm{mg}$ a week $(5,6)$. For CD, pituitarydirected therapy with the SRL pasireotide can be attempted to decrease ACTH and control adenoma growth (7). When maximal doses have been unsuccessful in controlling disease, further treatment options should be considered.

In the cases presented here, the 4 patients with prolactinomas received maximally tolerated doses of cabergoline ranging from 10.5 to $14 \mathrm{mg}$ a week, although the adenomas continued to progress and PRL levels remained elevated, necessitating additional therapeutic interventions. In one case of an SCA that converted to florid $\mathrm{CD}$, the patient received several medications, including ketoconazole, metyrapone, and mitotane, but hypercortisolism remained uncontrolled and she ultimately underwent bilateral adrenalectomy. The other CD patients underwent surgical resection of the recurrent adenoma without receiving prior medical therapy.

\section{SURGICAL RESECTION}

MRI evidence of total adenoma removal after initial surgery correlates with long-term disease-free survival in more than $90 \%$ of patients among patients with non-functioning adenomas (NFAs) (8-10). Even when residual tumor tissue is visible on postoperative MRI, approximately $60 \%$ to $70 \%$ of adenomas will show little evidence of regrowth over a period of approximately 10 years $(11,12)$; in these cases, regrowth occurs at a rate of approximately $1 \mathrm{~mm}$ per year. For functioning adenomas, recurrence of hormonal hypersecretion can occur in up to $25 \%$ of patients with CD and up to $40 \%$ of patients with prolactinomas at 5 years (13-15), for which re-operation or medical therapy is often effective.

By contrast, for patients with refractory adenomas, surgery plays a lesser role (16-19). These adenomas may invade the cavernous sinus, skull base, or intracranial structures beyond the sella and parasellar region, reducing the opportunity for gross total resection, and there is high likelihood of further growth even with extensive resection. On initial presentation, adenomas are more likely to have a soft texture and a pseudo-capsule, which is a thin, non-fibrotic band of tissue that surrounds and encapsulates the tissue, separating the tumor from the normal gland and other structures, allowing for "extracapsular" removal of the entire mass. However, recurrent adenomas are far more fibrotic and poorly encapsulated $(20,21)$, which, when combined with previous surgical scarring, makes surgical debulking far more challenging. Nonetheless, particularly for rapidly growing adenomas, reoperation can be considered to reduce mass effect, i.e., to decompress critical structures such as the pituitary gland or optic apparatus, in anticipation of subsequent radiation therapy (RT) or chemotherapy (22).

In general, there is no absolute limit to the number of times transsphenoidal surgery or craniotomy can be attempted, although potential benefits are typically diminished after 3-4 surgeries due to progression of tumor into areas in which surgical resection is difficult or tumor texture renders meaningful debulking impossible.

Among the 9 cases of aggressive adenoma, 4 patients underwent 3 surgeries, 3 had 4 surgeries, 1 patient had 2 surgeries, and 1 underwent surgery after progression on temozolomide (TMZ). While surgery was successful in debulking the adenoma in all cases, gross total resection was not achieved, and the residual adenoma continued to grow. This pattern of subtotal resection and growth of postoperative residual adenoma is typical of aggressive adenomas.

\section{RADIATION THERAPY}

RT has proven reliable when surgical resection is deemed not feasible or when medical therapy is no longer efficacious or 
TABLE 1 | Summary of cases

\begin{tabular}{|c|c|c|c|c|c|c|c|c|c|c|c|c|}
\hline Case & $\begin{array}{l}\text { Year of } \\
\text { Dx }\end{array}$ & $\begin{array}{c}\text { Age at } \\
\text { Dx }\end{array}$ & Sex & Type & Features* & Recurrences & Initial therapy & Surgery & RT & Medical therapy & Follow-up & $\begin{array}{l}\text { Disease } \\
\text { duration }\end{array}$ \\
\hline 1 & 1997 & 45 & M & $S C A \rightarrow C D$ & $\begin{array}{l}25 \mathrm{~mm} \text {, right cavernous sinus } \\
\text { invasion }\end{array}$ & 6 & TSS & $\begin{array}{l}1997 \\
\text { TSS } \\
2012 \\
\text { TSS } \\
2015 \\
\text { TSS }\end{array}$ & $\begin{array}{l}1998 \text { GK } \\
\text { SRS } \\
2010 \text { CK } \\
\text { SRS } \\
2015 \text { FRT } \\
2016 \\
\text { Proton SRS }\end{array}$ & $\begin{array}{l}\text { 2013: TMZ } \times 7 \text { cycles: PR } \\
\text { 2013: Pasireotide } \times 1 \text { 1yr: } \\
\text { SD } \\
\text { 2017: Bevacizumab } \times 3 \\
\text { mo: PD }\end{array}$ & $\begin{array}{l}\text { 2017: Transformed to carcinoma with cerebellar and cervical spine } \\
\text { metastases } \\
\text { 2018: Deceased }\end{array}$ & 21 yrs \\
\hline 2 & 2010 & 45 & $\mathrm{~F}$ & Null cell & $\begin{array}{l}19 \mathrm{~mm} \text {, left cavernous sinus } \\
\text { invasion }\end{array}$ & 2 & TSS & $\begin{array}{l}2010 \\
\text { TSS } \\
2011 \\
\text { TSS } \\
2012 \\
\text { TSS }\end{array}$ & $\begin{array}{l}2011 \text { IMRT } \\
2012 \text { IMRT }\end{array}$ & $\begin{array}{l}\text { 2011: TMZ x } 9 \text { cycles: PD } \\
\text { 2012: Lapatinib } \times 2 \text { yrs: } \\
\text { no recurrence }\end{array}$ & $\begin{array}{l}\text { 2012: Developed de novo orbital metastasis, consistent with } \\
\text { transformation to carcinoma } \\
\text { 2020: No tumor }\end{array}$ & $10 \mathrm{yrs}$ \\
\hline 3 & 2012 & 29 & M & PRLoma & $\begin{array}{l}90 \mathrm{~mm} \text {; left cavernous invasion, } \\
\text { mass effect on brainstem and } 4 \text { th } \\
\text { ventricle. }\end{array}$ & 5 & $\begin{array}{l}\text { Cab with maximum dose of } \\
10.5 \mathrm{mg} / \mathrm{week}\end{array}$ & $\begin{array}{l}2014 \\
\text { CRX } \\
2016 \\
\text { TSS } \\
2017 \\
\text { TSS } \\
2019 \\
\text { TSS }\end{array}$ & 2019 FRT & 2019: TMZ $\times 6$ cycles: SD & 2020: Stable residual tumor with no evidence of metastases & 8 yrs \\
\hline 4 & 2001 & 24 & $\mathrm{~F}$ & $\mathrm{SCA} \rightarrow \mathrm{CD}$ & $\begin{array}{l}59 \mathrm{~mm} \text {; invasion of right } \\
\text { cavernous sinus, Meckel's cave } \\
\text { and prepontine cistern }\end{array}$ & 6 & CRX & $\begin{array}{l}2001 \\
\text { CRX } \\
2002 \\
\text { TSS } \\
2007 \\
\text { CRX } \\
2008 \\
\text { CRX } \\
2014 \\
\text { BLA }\end{array}$ & $\begin{array}{l}2002 \text { GK } \\
\text { SRS } \\
2015 \text { FRT/ } \\
\text { TMZ }\end{array}$ & $\begin{array}{l}\text { 2014: TMZ × } 4 \text { cycles: SD } \\
\text { 2014: Pasireotide x } 2 \text { mo: } \\
\text { PD } \\
\text { Ketoconazole: PD } \\
\text { Metyrapone: PD } \\
\text { Mitotane: PD } \\
\text { 2016: Cabergoline: SD } \\
\text { Pasireotide: SD }\end{array}$ & $\begin{array}{l}\text { 2020: Decreased tumor size, ACTH } 134 \text { with no evidence of } \\
\text { metastases }\end{array}$ & $19 \mathrm{yrs}$ \\
\hline 5 & 2004 & 40 & M & $\mathrm{SCA} \rightarrow \mathrm{CD}$ & $\begin{array}{l}24 \mathrm{~mm} \text {; right cavernous sinus } \\
\text { invasion, encasing carotid }\end{array}$ & 2 & TSS & $\begin{array}{l}2004 \\
\text { TSS } \\
2013 \\
\text { TSS } \\
2015 \\
\text { CRX }\end{array}$ & $\begin{array}{l}2013 \mathrm{RT} \\
2015 \mathrm{RT} / \\
\text { TMZ }\end{array}$ & $\begin{array}{l}\text { 2015: TMZ × } 6 \text { cycles: PR } \\
\text { 2016: Bevacizumab x } 6 \\
\text { mo }\end{array}$ & 2019: No visible tumor and no evidence of metastases & 15 yrs \\
\hline 6 & 1996 & 56 & M & $C D$ & $28 \mathrm{~mm}$; clival invasion & 3 & TSS & $\begin{array}{l}1997 \\
\text { TSS } \\
1998 \\
\text { TSS } \\
2000 \\
\text { TSS } \\
2013 \\
\text { TSS }\end{array}$ & 2000 RT & & $\begin{array}{l}\text { 2015: No sellar tumor } \\
\text { New dural masses consistent with meningiomas }\end{array}$ & 18 yrs \\
\hline 7 & 1994 & 54 & M & PRLoma & $\begin{array}{l}40 \mathrm{~mm} \text {; in anterior foramen, right } \\
\text { infratemporal fossa, occipital } \\
\text { condyle }\end{array}$ & 3 & $\begin{array}{l}\text { Cab with maximum dose of } \\
14 \mathrm{mg} / \text { week }\end{array}$ & $\begin{array}{l}1996 \\
\text { TSS } \\
2005 \\
\text { TSS }\end{array}$ & $\begin{array}{l}1996 \text { GK } \\
\text { SRS }\end{array}$ & 2006: TMZ × 2 cycles: PD & $\begin{array}{l}\text { 2006: Developed metastatic disease to the skull base, neck, and lymph } \\
\text { node, consistent with carcinoma } \\
\text { Deceased }\end{array}$ & $12 \mathrm{yrs}$ \\
\hline 8 & 2009 & 20 & M & PRLoma & $\begin{array}{l}40 \mathrm{~mm} \text {; invasion of bilateral } \\
\text { cavernous sinuses, Meckel's cave }\end{array}$ & 1 & $\begin{array}{l}\text { Cab with maximum dose of } \\
10.5 \mathrm{mg} / \text { week }\end{array}$ & $\begin{array}{l}2021 \\
\text { TSS }\end{array}$ & & 2017: TMZ $\times 6$ cycles: PR & 2021: Tumor growth (pre-TSS) with no sign of metastatic disease & 12 yrs \\
\hline 9 & 2008 & 36 & M & PRLoma & $\begin{array}{l}40 \mathrm{~mm} \text {; bilateral cavernous } \\
\text { sinuses }\end{array}$ & 3 & $\begin{array}{l}\text { Cab with maximum dose of } \\
12 \mathrm{mg} / \text { week }\end{array}$ & $\begin{array}{l}2013 \\
\text { TSS } \\
2014 \\
\text { TSS } \\
2019 \\
\text { CRX }\end{array}$ & 2015 RT & $\begin{array}{l}\text { 2020: Octreotide } \\
\text { 2020: TMZ } \times 7 \text { cycles: PR }\end{array}$ & 2021: Decreased tumor size with no sign of metastatic disease & $13 \mathrm{yrs}$ \\
\hline
\end{tabular}

${ }^{*}$ Features of recurrent adenomas are listed if data were not available from initial presentation.

ACTH, adrenocorticotropin; BLA, bilateral adrenalectomy; Cab, cabergoline; CD, Cushing disease; CK, CyberKnife; CRX, craniotomy; Dx, diagnosis; FRT, fractionated radiation therapy; GK, GammaKnife; IMRT, intensity-modulated radiation therapy; PD, progressive disease; PRL, prolactin; PRLoma, prolactinoma; PR, partial response; RT, radiation therapy; SCA, silent corticotroph adenoma; SD, stable disease; SRS, stereotactic radiosurgery; TMZ, temozolomide; TSS transsphenoidal surgery; Yrs, years. 
TABLE 2 | Pathologic data.

\begin{tabular}{|c|c|c|c|c|}
\hline Case & Pathologic adenoma type & Ki-67 & Mitotic count & p53 \\
\hline 1 & Corticotroph & $5 \%$ & Not increased & Weakly positive \\
\hline 2 & Null cell & $10 \%$ & Many mitotic figures & positive \\
\hline 3 & Densely granulated lactotroph & $0.5 \%$ & Not increased & $60 \%$ positive $(1-2+)$ \\
\hline 4 & Null cell (initially) & Moderately high & Not increased & N/A \\
\hline 5 & Densely granulated corticotroph & $20 \%$ & rare & 80\% positive \\
\hline 6 & Densely granulated corticotroph & $1 \%$ & Not increased & $<0.5 \%$ \\
\hline 7 & Lactotroph & N/A & $\mathrm{N} / \mathrm{A}$ & N/A \\
\hline $8^{*}$ & $\mathrm{~N} / \mathrm{A}$ & N/A & $\mathrm{N} / \mathrm{A}$ & N/A \\
\hline 9 & Densely granulated lactotroph & $9 \%$ & Not increased & $<0.1 \%(1+)$ \\
\hline
\end{tabular}

*Patient underwent TSS for drainage of cyst. No viable tumor was visualized or resected; pathologic analysis therefore is not available (N/A).

tolerated (23-26). Treatment doses in the range of 12-15 Gy delivered in a single fraction or in multiple fractions can prevent further adenoma growth in more than 95\% of adenomas. However, rates of radiation-induced hypopituitarism are quite significant, with at least $25 \%$ and up to $90 \%$ of patients developing a degree of anterior pituitary hormone deficiency within 10 years $(25,27,28)$. In addition, other factors such as patient age, symptoms, adenoma aggressivity, and adenoma type must be taken into consideration when weighing treatment benefit and timing. RT also can be used to reduce hormone secretion in nonresectable functioning adenomas that have failed to respond to medical therapy or that demonstrate feedbackinduced adenoma growth (e.g., Nelson's syndrome in patients with progressive CD) (29-31).

A role for repeat irradiation of adenomas that progress or recur despite previous RT is far more limited due to substantial risk of radiation necrosis to adjacent brain structures or breakdown of the carotid artery wall leading to catastrophic bleeding or death $(32,33)$. The overlap between new and old radiation treatment fields as well as the time between radiation treatments should be considered when determining the potential risk-benefit ratio of additional RT. Improved planning software, more accurate treatment devices, and better understanding of adenoma physiology has allowed for lower radiation dose, which, in turn has resulted in reduced long-term secondary risk such as cognitive deterioration or carotid injury. Nonetheless, the absolute dose tolerance of brain and surrounding structures typically limits use to one or two sessions.

Eight of our 9 patients had RT immediately after initial surgery or after multiple surgeries: 4 patients had a single course, 3 had 2 courses, and 1 had 4 courses. Five patients initially responded to RT, demonstrating either stable disease or some decrease in size, while the remaining 3 patients had continued progressive disease despite RT. All patients showed disease recurrence/progression over time.

\section{TEMOZOLOMIDE}

TMZ demonstrates clinical efficacy in up to one-third of aggressive adenomas and its use in these cases is widely reported (34). TMZ is recommended for aggressive pituitary adenomas that grow despite surgery, RT, and optimized medical therapy (3). TMZ may also be considered in frail patients who may not tolerate repeat surgery or have relative contraindications to RT (35). However, the timing of treatment initiation, the duration of therapy, and the potential additive benefits of combining TMZ with RT or another agent all remain unknown.

The standard treatment schedule for TMZ monotherapy is $150-200 \mathrm{mg} / \mathrm{m}^{2} /$ day for 5 days every 4 weeks. Regimens that administer lower TMZ doses for longer periods in a cycle, such as $50 \mathrm{mg} / \mathrm{m}^{2}$ daily for 21 days (36), have been associated with increased myelotoxicity (37). In patients where the combination of TMZ with RT is considered, such as in those with rapidly growing adenomas with elevated Ki-67 $>10 \%$, extensive p53 expression, and/or high mitotic count (3), TMZ can be initiated at lower doses during and then escalated after RT. For example, treatment may be administered as 6 weeks of continuous TMZ therapy at $75 \mathrm{mg} / \mathrm{m}^{2}$ daily with RT, followed by 6-12 months of standard TMZ monotherapy at $150 \mathrm{mg} / \mathrm{m}^{2}$ daily for 5 days every 28 days and increasing as tolerated to 200 $\mathrm{mg} / \mathrm{m}^{2}$ (38). Among 166 patients with aggressive pituitary adenomas treated by 67 surveyed members of the European Endocrine Society (ESE), 14 patients received concomitant TMZ and RT with complete or partial response observed in $71 \%$ compared to $34 \%$ in those on TMZ monotherapy (39), suggesting the efficacy of combination therapy.

Treatment efficacy with TMZ is typically evident by 3 months (40), although many patients may not see maximal adenoma response until 6 months (39). Of note, biochemical response often parallels response on MRI, and may even improve further once adenoma growth stabilizes $(39,41)$. In the ESE survey, complete radiologic response, i.e., no visible adenoma, was observed in $6 \%$ and complete biochemical response in $19 \%$ of cases, while partial radiologic response with $>30 \%$ reduction in size was seen in $31 \%$ and partial biochemical response with $>20 \%$ hormone reduction in $24 \%$ of cases (39). A systematic review of TMZ in aggressive pituitary adenomas and carcinomas showed similar response rates, with $6.5 \%$ of 31 aggressive adenomas achieving complete response, $45 \%$ partial response, $29 \%$ stable disease, and $19 \%$ progressive disease, while $8.7 \%$ of 23 pituitary carcinomas showed complete response, $61 \%$ partial response, $13 \%$ stable disease, and $17 \%$ progressive disease (42).

TMZ therapy is usually administered for 6 months (3), although case reports describe up to 12 months of treatment. Median treatment duration of 9 months in the ESE survey was 
associated with treatment response (39). A study of 30 adenomas treated with at least 6 cycles of TMZ showed that $27 \%$ had adenoma regression, $47 \%$ stable disease, and $27 \%$ adenoma progression. After a medial follow-up of 34 months, $40 \%$ maintained stable disease and $60 \%$ had progression (41).

Longer duration of TMZ treatment has been shown to be beneficial in maintaining disease-free progression up to 120 months (42). However, it can be difficult to quantify because reports describe widely varying treatment durations. In a multicenter study, patients treated for more than 12 months with TMZ had a median relapse-free survival of 57 months versus 18 months for those treated for 12 months or less (43), suggesting the benefit with "longer-term" therapy is seen after 12 months. By contrast, the systematic review of 31 aggressive adenomas and 23 carcinomas defined "short-term" TMZ treatment as a median of 8 months (range, 1-12 cycles) and "long-term" as a median of 26 months (range, 14-45) cycles. Among patients who responded, $36 \%$ were receiving long term TMZ; 5-year progression-free survival rate was numerically but not significantly different at $61.3 \%$ for long-term TMZ compared to $16.3 \%$ for short-term TMZ, but overall survival rate was significantly improved with long-term therapy $(91.7 \%$ vs $54.1 \%$; $\mathrm{p}=0.08$ ). Of note, $95 \%$ of patients had received prior RT and $75 \%$ were previously treated with other standard therapies (42). In a report of 8 patients with aggressive adenomas treated with TMZ for more than 12 months, 4 patients had partial response and the other 4 had stable disease; response was maintained while on TMZ. Of the 3 patients with ACTHsecreting adenomas, one showed complete remission of hypercortisolism, one with Nelson's syndrome showed $>90 \%$ reduction in $\mathrm{ACTH}$ level, and the third showed $\sim 40 \%$ reduction in ACTH and urinary free cortisol (44).

Based on available reports, it is reasonable to consider continued TMZ therapy beyond 6 months in patients who are responding to treatment.

The combination of TMZ with the oral chemotherapy capecitabine in the CAPTEM protocol has shown some efficacy in aggressive CD. In a report of 4 cases, 2 had complete adenoma resolution, 1 stable disease, and 1 a $75 \%$ decrease in adenoma size concomitant with ACTH reduction (45); another reported case of CAPTEM in an aggressive CD patient showed radiologic stable disease and biochemical response (39). However, use of CAPTEM in 2 corticotroph carcinomas and one lactotroph carcinoma were not successful $(39,40)$.

MGMT status has been proposed as a predictor of response to TMZ therapy. MGMT (O6-methyl guanine DNA methyl transferase) is a DNA repair enzyme that negates the effect of TMZ (34) and thus tumoral expression of MGMT is inversely related to TMZ efficacy (40, 46-48). However, patients with high MGMT expression may still respond to $\operatorname{TMZ}(36,43,49)$; in the ESE survey, $76 \%$ of those with low MGMT expression responded, while $46 \%$ with high MGMT expression did not (39). Therefore, TMZ should still be considered, regardless of MGMT status (3). Functioning aggressive adenomas have been shown to respond better to TMZ compared to NFAs (45\% vs $17 \%)$, although the rationale is unknown (39).
A second course of TMZ is usually less effective than the initial course and response has not been consistently demonstrated $(39,43,50)$. However, it may be reasonable to attempt a 3-month rechallenge in patients with late relapse and low MGMT, as a report of 9 adenomas treated with a second course of TMZ showed that late relapse after the first course was associated with improved response (34).

Eight of the 9 cases presented here were treated with TMZ. Three patients with SCA that progressed to CD were treated with 4-6 cycles of TMZ, but response varied widely, likely due to both MGMT status and prior/concurrent treatments. One patient with 95\% MGMT expression showed radiologic progression after 2 cycles of TMZ. However, the addition of pasireotide enabled biochemical and radiologic response, and he completed 7 cycles of combination treatment before showing signs of relapse. The second patient underwent RT followed by 6 cycles of TMZ and experienced both biochemical and radiologic improvement. MGMT in this patient was negative. The third patient, with an unknown MGMT status, showed both biochemical and radiologic response after 2 cycles but progressed again after 4 cycles. Of 4 patients with prolactinoma, one with an unknown MGMT status showed disease progression after concurrent administration of TMZ and RT followed by TMZ monotherapy for 1 cycle. However, the other 3 patients showed sustained biochemical and radiologic response to 6 cycles of TMZ; MGMT was $1 \%$ positive in 2 cases and unknown in the other. Finally, 1 patient with a null cell adenoma underwent RT and 9 cycles of TMZ before the disease progressed. MGMT at the initial surgery and upon removal of an orbital metastasis was $98 \%$ positive.

Thus, of 8 patients treated, 2 had initial response but progressed after 4-6 cycles of TMZ, 1 did not respond at all, and 4 had partial response to TMZ.

\section{SRL THERAPY}

Clinical response of aggressive pituitary adenomas to SRLs is variable. Somatostatin receptor subtype (SST) expression and differences in SRL affinity for each SST may provide some insight into the likelihood of response. Corticotroph adenomas primarily express SST5, and octreotide and lanreotide, which have a strong affinity for SST2, are largely ineffective (51). Pasireotide, which has a stronger affinity for SST5, has been shown to normalize cortisol levels in $20-40 \%$ of CD patients (51). However, reports of aggressive CD treated with pasireotide show minimal effect (39). Of the reported 22 aggressive adenomas treated with pasireotide, only 4 (18\%) adenomas showed adenoma response and $5(23 \%)$ showed biochemical response $(39,50,52)$. In a report of 3 patients with aggressive ACTHsecreting macroadenoma or carcinoma, 2 showed paradoxical increase in ACTH and urinary free cortisol with pasireotide treatment (53), while another report of 3 patients with recurrent CD after cessation of TMZ showed no effect of pasireotide (50). However, one case of an SCA showed a $6 \%$ adenoma volume decrease with TMZ and a $21 \%$ decrease after adding pasireotide, 
and a $\mathrm{CD}$ patient showed biochemical response to pasireotide 12 months after partial response to TMZ (52). Some reports show pasireotide reduced ACTH secretion and adenoma size in some patients with Nelson's syndrome (54), but others show no response (55) or mixed response, with 5 patients in one series showing minimal impact on adenoma volume with pasireotide even though ACTH levels decreased (56).

Pasireotide was administered in 2 SCA cases that progressed to $\mathrm{CD}$. In 1 patient it was added to TMZ and enabled adenoma stabilization for a year. In the second patient, it was added after bilateral adrenalectomy and subsequent RT, and has maintained stabilization of both adenoma volume and ACTH levels for 4 years.

NFAs primarily express SST3 (57). Although octreotide and lanreotide may inhibit cell proliferation in cultured NFAs (58), clinical efficacy is limited. In 39 patients with residual adenoma tissue, $81 \%$ of those with positive octreotide uptake on scintigraphy demonstrated stable adenoma volumes with octreotide LAR treatment, but none had adenoma reduction (59). In a review of 100 NFAs in 11 published studies treated with octreotide for an average of 6 months, 12\% showed adenoma reduction, $83 \%$ stable residual, and 5\% increased volume (60). Although pasireotide has a higher affinity for SST3 and has been shown to inhibit NFA cell viability in vitro (61), no clinical studies have confirmed control of adenoma growth. Of note, there was no clear association between SST expression and clinical features of aggressiveness in 113 NFAs, of which $46 \%$ were invasive (62).

Prolactinomas show poor clinical response to SRLs and treatment of cultured DA-resistant adenomas did not show reduced prolactin (PRL) levels (63). However, clinical improvement has been demonstrated in some patients with confirmed SST5 expression. In 5 patients with DA-resistant prolactinomas, treatment with octreotide LAR and cabergoline reduced PRL levels in 2 patients, with a 93\% reduction in adenoma size; SST5 expression was noted in 1 responder (64). Others reported PRL and/or adenoma response in prolactinomas treated with combination cabergoline and pasireotide, including in an aggressive prolactinoma strongly positive for SST5 that demonstrated PRL normalization after 2 months that was maintained for 31 months, with $>50 \%$ reduction in adenoma size (65), as well as in a cabergoline-resistant giant silent prolactinoma showing high expression of SST5 that demonstrated adenoma shrinkage with pasireotide treatment (66). However, among 47 macroprolactinomas, SST2 and SST5 were expressed in only $3 / 23$ and $3 / 21$ adenomas, respectively, and 1 adenoma with both subtypes (66).

Of the 4 prolactinomas in the set, 1 showed continued adenoma growth and rising PRL levels despite cabergoline dose up to $7 \mathrm{mg}$ /day, multiple surgeries, and RT. Although SST5 expression was negative, he was started on octreotide LAR $30 \mathrm{mg}$ monthly in an attempt to stabilize PRL levels, but PRL remained elevated and adenoma size increased.

Peptide receptor radionuclide therapy (PRRT), an SRL-based therapy in which radiolabeled SST-binding molecules target SST2 and SST5, has been evaluated in aggressive pituitary adenomas, demonstrating octreotide uptake on PET/CT. Although $50 \%$ of NFAs, $38 \%$ of prolactinomas, and $50 \%$ of CD adenomas demonstrated positive uptake with ${ }^{111}$ In-octreotide scintigraphy (67), only 3 of 20 aggressive pituitary adenomas treated with PRRT, showed a partial response and 3 stable disease (reviewed in [68)].

\section{EGFR-, VEGF-, AND MTOR-TARGETING THERAPY}

Another target for aggressive pituitary adenomas is EGFR, which belongs to the ErbB family of membrane receptor kinases (69). To date, 3 EGFR tyrosine kinase inhibitors (TKIs), gefitinib, lapatinib, and canertinib, have been evaluated in the treatment of pituitary adenomas. Gefitinib selectively inhibits EGFR/ErbB1 activity, lapatinib prevents activation of EGFR/ErbB2, and canertinib is an experimental pan-ErbB receptor TKI (70).

EGFR is expressed in $75 \%$ of human corticotroph adenomas $(69,71)$, and gefitinib treatment of human primary pituitary corticotroph tumor cultures reduced POMC mRNA and reversed features of hypercortisolemia (71). Lapatinib treatment of corticotroph tumor cells decreased POMC mRNA and ACTH levels. Canertinib, which targets multiple ErbB receptors, suppressed POMC mRNA and ACTH secretion in cultured human corticotroph adenomas, with a $70 \%$ reduction seen in those with higher ErbB expression (72).

Gain-of-function mutations in USP8 have been implicated in aberrant EGFR signaling in corticotrophs (73-75) and studies show USP8 mutations in 21-62\% of corticotroph adenomas (76). However, it remains unclear whether USP8 mutations and EGFR overexpression are associated with more aggressive adenomas (73, 75, 77-79). Whole exome sequencing of corticotroph adenomas enriched with aggressive adenomas identified USP8 mutations in only 5 of 22 adenomas (80), but another study found EGFR expression in the cytoplasm of 29 of 52 CD adenomas, and protein expression associated with recurrence (81). There are as yet no reports of EGFR-targeting therapy in patients with aggressive CD.

The strongest evidence supporting use of these agents is for aggressive prolactinomas. EGFR, ErbB2, and ErbB3 are all endogenously expressed in rat lacto-somatotroph tumor cells, and in vitro treatment with EGFR TKIs was shown to prevent PRL secretion $(69,82,83)$. GH3 cell lines transfected with a constitutively active form of ErbB2 showed a 250-fold induction of PRL, while treatment of these cells with lapatinib led to $40 \%$ suppression of PRL secretion (82). In Wistar-Furth rats inoculated with these same transfectants, treatment with lapatinib led to a $40 \%$ suppression of adenoma growth and $50 \%$ decrease in PRL levels (82), and Fischer rats implanted with estrogen pellets to recapitulate an endogenous prolactinoma model developed pituitary adenomas with hyperprolactinemia that were suppressed by $35 \%$ with lapatinib treatment (82). More than $50 \%$ of prolactinomas express EGFR and 25\% express ErbB2 protein (reviewed in (69), with $40 \%$ of invasive adenomas staining positive for ErbB2, compared to $1.2 \%$ of 
noninvasive adenomas (84). However, rates of ErbB receptor expression were even higher in 28 human prolactinoma specimens analyzed (85), with approximately 80\% expressing ErbB receptors, including EGFR (82\%), ErbB2 (92\%), ErbB3 (25\%), and ErbB4 (71\%). Higher ErbB3 receptor expression correlated with higher rates of optic chiasm compression, suprasellar extension, and encasement of the carotids, while higher ErbB4 was observed in adenomas with sphenoid sinus invasion (85).

In a 6-month proof-of-concept clinical trial, patients with DA-resistant prolactinomas were treated with lapatinib. One subject demonstrated near normalization of PRL and a $22 \%$ reduction in adenoma volume after showing continued adenoma growth and PRL elevation on cabergoline $7 \mathrm{mg} /$ week and surgical adenoma resection; a second subject with persistent hyperprolactinemia and adenoma growth on cabergoline $7 \mathrm{mg}$ / week and surgical resection achieved a $42 \%$ reduction in PRL and tumor size stabilization (85).

In a follow-up phase IIa trial, 3 of 4 patients with aggressive prolactinomas treated with 6 months of lapatinib showed stable radiologic disease, with 1 subject showing up to $17 \%$ decrease in diameter and a $42 \%$ decrease in PRL (86). EGFR expression did not correlate with response to lapatinib therapy.

The 1 patient with a null cell adenoma was treated for 2 years with lapatinib following surgery and RT for an orbital metastasis to help prevent recurrence. After 8 years, she continues to show no signs of recurrence. Her adenoma was positive for EGFR and ErbB2 on immunohistochemistry.

VEGF, expressed in pituitary adenomas, stimulates angiogenesis and regulates the tumor microenvironment to contribute to pituitary tumorigenesis $(43,87,88)$. However, treatment of aggressive pituitary adenomas with bevacizumab, a monoclonal antibody binding VEGFR, has yielded mixed results. The ESE survey reported adenoma stabilization in 1 of 3 patients on bevacizumab monotherapy, with another showing partial adenoma regression after combination therapy with TMZ, while a third showed adenoma progression (39). Treatment with bevacizumab after multiple prior therapies including temozolomide in 2 patients with corticotroph adenomas showed decreased ACTH after the first cycle but no longer-term benefit, while 1 patient with NFA showed disease stabilization for 18 months (89).

VEGF-targeting agents in combination with RT and TMZ demonstrated stabilization of a silent corticotroph carcinoma (90), as well as prolonged recurrence-free survival after treatment with RT, TMZ, and bevacizumab (91); progression-free survival for 8 years was observed after RT, TMZ, and bevacizumab in a corticotroph carcinoma with CNS metastases (92). Treatment of 17 pituitary carcinoma patients who recurred after TMZ use also showed some response to bevacizumab monotherapy or combination therapy, including 1 patient with a null cell carcinoma who remains on bevacizumab (93).

Bevacizumab was attempted in 2 patients in our series, both of whom have SCAs that progressed to CD. One had failed multiple courses of RT and showed spinal and dural metastases when he was started on bevacizumab. After 3 months on therapy, he developed cognitive decline, transitioned to hospice, and died. The other patient was started on bevacizumab after undergoing 3 surgeries and 2 courses of RT as well as TMZ. Treatment was given for 6 cycles and he remains recurrence-free 15 years after his initial diagnosis. VEGF expression status was unknown.

The mTOR inhibitor everolimus, approved for the treatment of neuroendocrine tumors, exhibits antiproliferative and proapoptotic activity in pituitary adenomas (94). Clinical response to everolimus is variable, with reports describing partial response in a prolactinoma and stable disease in a corticotroph carcinoma, but progressive disease in 4 other cases of aggressive adenomas (39, 95-97) (Table 3).

\section{SUMMARY OF TREATMENT OPTIONS}

Treatment of aggressive pituitary adenomas is challenging. The rarity of the disorder, heterogeneity of aggressive adenomas, the lack of consistent response to treatment options, and limited experience on when and how to initiate each treatment modality all underscore the need to individualize management. The cases presented here illustrate the importance of applying an individualized, multidisciplinary approach within the context of current evidence-based guidelines (Table 4).

Surgical resection and repeat adenoma debulking are recommended where feasible, especially when mass effects are evident. However, rapid re-growth of residual adenoma tissue requires use of additional therapy. RT, although not curative, may stabilize adenoma growth for months to years, with eventual progression. TMZ is effective in most patients, but responses may be partial and not sustained. Repeat treatment with TMZ is often less effective. Other medical therapies, including SRLs and EGFR-, VEGF-, and mTOR-targeting agents, may stabilize adenoma size and maintain biochemical control in patients with functioning adenomas, but evidence for this is limited. It

TABLE 3 | Summary of responses to targeted medical therapies.

\begin{tabular}{lccc}
\hline Therapy & N & Tumor response & Biochemical response \\
\hline EGFR-targeting gefitinib, lapatinib, canertinib & 8 & $25 \%(n=2)$ decrease & $50 \%(n=4)$ stable \\
& & $26 \%(n=4)$ stable & $38 \%(n=3)$ \\
VEGF-targeting bevacizumab & 15 & $14 \%(n=1)$ partial; \\
mTOR-targeting everolimus & 7 & $14 \%(n=1)$ stable & $25 \%(n=2)$
\end{tabular}

Data from McCormack et al, 2018 (39), Cooper et al, 2021 (86), Osterhage et al, 2021 (89), Ortiz et al, 2012 (90), Touma et al, 2017 (91), Donovan et al, 2016 (96), and Zhang et al, 2019 (97). 
TABLE 4 | Summary of treatment options.

\begin{tabular}{|c|c|}
\hline Treatment option & Clinical Considerations \\
\hline Surgery & $\begin{array}{l}\text { - Total gross resection and/or adenoma debulking preferred where feasible } \\
\text { - } \quad \text { No upper limit on number of surgeries, although scarring and adenoma location and texture may limit benefits after 3-4 }\end{array}$ \\
\hline $\mathrm{RT}$ & $\begin{array}{l}\text { - Typically highly effective in controlling nonresectable adenoma growth } \\
\text { - } \quad \text { For repeat irradiation, careful planning is required to avoid injury to surrounding structures }\end{array}$ \\
\hline $\mathrm{TMZ}$ & $\begin{array}{l}\text { - } \quad \text { Recommended for adenoma that grow despite surgery, RT, and optimized medical therapy } \\
\text { - } \quad \text { Most common regimens: standard dose for } 6 \text { cycles if monotherapy, lower dose if given with RT } \\
\text { - } \quad \text { Rechallenge after progression is typically less effective } \\
\text { - } \quad \text { Longer duration of therapy may sustain response }\end{array}$ \\
\hline$S R L$ & $\begin{array}{l}\text { - Octreotide and lanreotide typically not effective } \\
\text { - } \quad \text { Pasireotide has limited effect in aggressive CD, may be effective in prolactinoma } \\
\text { - } \quad \text { Unclear whether SST5 expression is useful in predicting response }\end{array}$ \\
\hline EGFR-targeting & $\begin{array}{l}\text { - } \quad \text { Best evidence for efficacy is with lapatinib in prolactinoma } \\
\text { - } \quad \text { Optimal timing of initiation and treatment duration are unclear }\end{array}$ \\
\hline VEGF-targeting & $\begin{array}{l}\text { - } \quad \text { Bevacizumab shows mixed results } \\
\text { - } \quad \text { Combination with RT and/or TMZ may be effective for pituitary carcinomas or some aggressive CD converted from SCA }\end{array}$ \\
\hline
\end{tabular}

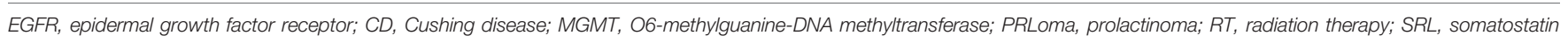
receptor ligand; SST, somatostatin receptor; TMZ, temozolomide; VEGF, vascular endothelial growth factor.

is unclear whether initiation of these therapies before adenoma growth is evident may help delay progression, allowing TMZ therapy to be 'reserved' when deemed clinically necessary. Identification of actionable molecular targets in aggressive adenomas may further help determine whether other kinase inhibitors and checkpoint inhibitors can be of additional benefit $(80,98)$. Importantly, regardless of whether an adenoma is defined as aggressive, some subtypes may show aggressive behavior and may warrant use of aggressive treatment strategies. These include SCA that evolve to clinically apparent $\mathrm{CD}$, and lactotroph tumors in males that show resistance to dopamine agonist therapy. Continued study of aggressive

\section{REFERENCES}

1. Lopes MBS. The 2017 World Health Organization Classification of Tumors of the Pituitary Gland: A Summary. Acta Neuropathol (2017) 134(4):521-35. doi: 10.1007/s00401-017-1769-8

2. Melmed S. Pituitary-Tumor Endocrinopathies. N Engl J Med (2020) 382 (10):937-50. doi: 10.1056/NEJMra1810772

3. Raverot G, Burman P, McCormack A, Heaney A, Petersenn S, Popovic V, et al. European Society of Endocrinology Clinical Practice Guidelines for the Management of Aggressive Pituitary Tumours and Carcinomas. Eur J Endocrinol (2018) 178(1):G1-G24. doi: 10.1530/ EJE-17-0796

4. Casanueva FF, Barkan AL, Buchfelder M, Klibanski A, Laws ER, Loeffler JS, et al. Criteria for the Definition of Pituitary Tumor Centers of Excellence (PTCOE): A Pituitary Society Statement. Pituitary (2017) 20(5):489-98. doi: 10.1007/s11102-017-0838-2

5. Melmed S, Casanueva FF, Hoffman AR, Kleinberg DL, Montori VM, Schlechte JA, et al. Diagnosis and Treatment of Hyperprolactinemia: An Endocrine Society Clinical Practice Guideline. J Clin Endocrinol Metab (2011) 96(2):273-88. doi: 10.1210/jc.2010-1692

6. Ono M, Miki N, Kawamata T, Makino R, Amano K, Seki T, et al. Prospective Study of High-Dose Cabergoline Treatment of Prolactinomas in 150 Patients. J Clin Endocrinol Metab (2008) 93(12):4721-7. doi: 10.1210/ jc. $2007-2758$

7. Nieman LK, Biller BM, Findling JW, Murad MH, Newell-Price J, Savage MO, et al. Treatment of Cushing's Syndrome: An Endocrine Society Clinical pituitary adenomas is essential to establishing a treatment paradigm that maintains adenoma control while optimizing patient quality of life.

\section{AUTHOR CONTRIBUTIONS}

OC and AM conceptualized the project, performed the literature search and data analysis, and drafted the article. OC, VB, and NAL contributed case discussions. All authors contributed to the article and approved the submitted version.
Practice Guideline. J Clin Endocrinol Metab (2015) 100(8):2807-31. doi: 10.1210/jc.2015-1818

8. Gondim JA, Schops M, de Almeida JP, de Albuquerque LA, Gomes E, Ferraz T, et al. Endoscopic Endonasal Transsphenoidal Surgery: Surgical Results of 228 Pituitary Adenomas Treated in a Pituitary Center. Pituitary (2010) 13 (1):68-77. doi: 10.1007/s11102-009-0195-x

9. Ludecke DK, Abe T. Transsphenoidal Microsurgery for Newly Diagnosed Acromegaly: A Personal View After More Than 1,000 Operations. Neuroendocrinology (2006) 83(3-4):230-9. doi: 10.1159/000095533

10. Mamelak AN, Carmichael J, Bonert VH, Cooper O, Melmed S. Single-Surgeon Fully Endoscopic Endonasal Transsphenoidal Surgery: Outcomes in ThreeHundred Consecutive Cases. Pituitary (2013) 16(3):393-401. doi: 10.1007/ s11102-012-0437-1

11. Dekkers OM, Hammer S, de Keizer RJ, Roelfsema F, Schutte PJ, Smit JW, et al. The Natural Course of Non-Functioning Pituitary Macroadenomas. Eur J Endocrinol (2007) 156(2):217-24. doi: 10.1530/eje.1.02334

12. Dekkers OM, Pereira AM, Roelfsema F, Voormolen JH, Neelis KJ, Schroijen MA, et al. Observation Alone After Transsphenoidal Surgery for Nonfunctioning Pituitary Macroadenoma. J Clin Endocrinol Metab (2006) 91(5):1796-801. doi: 10.1210/jc.2005-2552

13. Burke WT, Penn DL, Castlen JP, Donoho DA, Repetti CS, Iuliano S, et al. Prolactinomas and Nonfunctioning Adenomas: Preoperative Diagnosis of Tumor Type Using Serum Prolactin and Tumor Size. J Neurosurg (2020) 133 (2)321-328. doi: 10.3171/2019.3JNS19121

14. Rees DA, Hanna FW, Davies JS, Mills RG, Vafidis J, Scanlon MF. Long-Term Follow-Up Results of Transsphenoidal Surgery for Cushing's Disease in a 
Single Centre Using Strict Criteria for Remission. Clin Endocrinol (Oxf) (2002) 56(4):541-51. doi: 10.1046/j.1365-2265.2002.01511.x

15. Roelfsema F, Biermasz NR, Pereira AM. Clinical Factors Involved in the Recurrence of Pituitary Adenomas After Surgical Remission: A Structured Review and Meta-Analysis. Pituitary (2012) 15(1):71-83. doi: 10.1007/ s11102-011-0347-7

16. Benveniste RJ, King WA, Walsh J, Lee JS, Delman BN, Post KD. Repeated Transsphenoidal Surgery to Treat Recurrent or Residual Pituitary Adenoma. J Neurosurg (2005) 102(6):1004-12. doi: 10.3171/jns.2005.102.6.1004

17. Kurosaki M, Luedecke DK, Abe T. Effectiveness of Secondary Transnasal Surgery in GH-Secreting Pituitary Macroadenomas. Endocr J (2003) 50 (5):635-42. doi: 10.1507/endocri.50.635

18. Almeida JP, Ruiz-Trevino AS, Liang B, Omay SB, Shetty SR, Chen YN, et al. Reoperation for Growth Hormone-Secreting Pituitary Adenomas: Report on an Endonasal Endoscopic Series With a Systematic Review and Meta-Analysis of the Literature. J Neurosurg (2018) 129(2):404-16. doi: 10.3171/ 2017.2.JNS162673

19. Delgado-Lopez PD, Pi-Barrio J, Duenas-Polo MT, Pascual-Llorente M, Gordon-Bolanos MC. Recurrent Non-Functioning Pituitary Adenomas: A Review on the New Pathological Classification, Management Guidelines and Treatment Options. Clin Transl Oncol (2018) 20(10):1233-45. doi: 10.1007/ s12094-018-1868-6

20. Galm BP, Martinez-Salazar EL, Swearingen B, Torriani M, Klibanski A, Bredella MA, et al. MRI Texture Analysis as a Predictor of Tumor Recurrence or Progression in Patients With Clinically Non-Functioning Pituitary Adenomas. Eur J Endocrinol (2018) 179(3):191-8. doi: 10.1530/ EJE-18-0291

21. Wei L, Lin SA, Fan K, Xiao D, Hong J, Wang S. Relationship Between Pituitary Adenoma Texture and Collagen Content Revealed by Comparative Study of MRI and Pathology Analysis. Int J Clin Exp Med (2015) 8(8):12898-905.

22. Forster N, Warnick R, Takiar V, Pater L, Breneman J. Debulking Surgery of Pituitary Adenoma as a Strategy to Facilitate Definitive Stereotactic Radiosurgery. J Neurooncol (2018) 138(2):335-40. doi: 10.1007/s11060-0182801-0

23. Minniti G, Flickinger J. The Risk/Benefit Ratio of Radiotherapy in Pituitary Tumors. Best Pract Res Clin Endocrinol Metab (2019) 33(2):101269. doi: 10.1016/j.beem.2019.04.003

24. Heringer LC, Machado de Lima M, Rotta JM, Botelho RV. Effect of Stereotactic Radiosurgery on Residual or Relapsed Pituitary Adenoma: A Systematic Review and Meta-Analysis. World Neurosurg (2020) 136:37481.e4. doi: 10.1016/j.wneu.2019.11.041

25. Sheehan JP, Niranjan A, Sheehan JM, Jane JAJr., Laws ER, Kondziolka D, et al. Stereotactic Radiosurgery for Pituitary Adenomas: An Intermediate Review of Its Safety, Efficacy, and Role in the Neurosurgical Treatment Armamentarium. J Neurosurg (2005) 102(4):678-91. doi: 10.3171/jns.2005.102.4.0678

26. Swearingen B, Barker FG2nd, Katznelson L, Biller BM, Grinspoon S, Klibanski A, et al. Long-Term Mortality After Transsphenoidal Surgery and Adjunctive Therapy for Acromegaly. J Clin Endocrinol Metab (1998) 83(10):3419-26. doi: $10.1210 /$ jc. 83.10 .3419

27. Pollack IF, Claassen D, al-Shboul Q, Janosky JE, Deutsch M. Low-Grade Gliomas of the Cerebral Hemispheres in Children: An Analysis of 71 Cases. J Neurosurg (1995) 82(4):536-47. doi: 10.3171/jns.1995.82.4.0536

28. Ding D, Starke RM, Sheehan JP. Treatment Paradigms for Pituitary Adenomas: Defining the Roles of Radiosurgery and Radiation Therapy. J Neurooncol (2014) 117(3):445-57. doi: 10.1007/s11060-013-1262-8

29. Mehta GU, Ding D, Patibandla MR, Kano H, Sisterson N, Su YH, et al. Stereotactic Radiosurgery for Cushing Disease: Results of an International, Multicenter Study. J Clin Endocrinol Metab (2017) 102(11):4284-91. doi: 10.1210/jc.2017-01385

30. Tritos NA, Biller BM, Swearingen B. Management of Cushing Disease. Nat Rev Endocrinol (2011) 7(5):279-89. doi: 10.1038/nrendo.2011.12

31. Vladyka V, Liscak R, Novotny JJr., Marek J, Jezkova J. Radiation Tolerance of Functioning Pituitary Tissue in Gamma Knife Surgery for Pituitary Adenomas. Neurosurgery (2003) 52(2):309-16; discussion 16-7. doi: 10.1227/01.NEU.0000043709.53906.31

32. Alonso CE, Bunevicius A, Trifiletti DM, Larner J, Lee CC, Pai FY, et al. Safety and Efficacy of Repeat Radiosurgery for Acromegaly: An International Multi-
Institutional Study. J Neurooncol (2019) 145(2):301-7. doi: 10.1007/s11060019-03296-8

33. Schoenthaler R, Albright NW, Wara WM, Phillips TL, Wilson CB, Larson DA. Re-Irradiation of Pituitary Adenoma. Int J Radiat Oncol Biol Phys (1992) 24(2):307-14. doi: 10.1016/0360-3016(92)90686-C

34. Burman P, Lamb L, McCormack A. Temozolomide Therapy for Aggressive Pituitary Tumours - Current Understanding and Future Perspectives. Rev Endocr Metab Disord (2020) 21(2):263-76. doi: 10.1007/s11154-020-09551-y

35. Whitelaw BC. How and When to Use Temozolomide to Treat Aggressive Pituitary Tumours. Endocr Relat Cancer (2019) 26(9):R545-R52. doi: 10.1530/ ERC-19-0083

36. Bush ZM, Longtine JA, Cunningham T, Schiff D, Jane JAJr., Vance ML, et al. Temozolomide Treatment for Aggressive Pituitary Tumors: Correlation of Clinical Outcome With O(6)-Methylguanine Methyltransferase (MGMT) Promoter Methylation and Expression. J Clin Endocrinol Metab (2010) 95 (11):E280-90. doi: 10.1210/jc.2010-0441

37. Gilbert MR, Wang M, Aldape KD, Stupp R, Hegi ME, Jaeckle KA, et al. DoseDense Temozolomide for Newly Diagnosed Glioblastoma: A Randomized Phase III Clinical Trial. J Clin Oncol (2013) 31(32):4085-91. doi: 10.1200/ JCO.2013.49.6968

38. Stupp R, Mason WP, van den Bent MJ, Weller M, Fisher B, Taphoorn MJ, et al. Radiotherapy Plus Concomitant and Adjuvant Temozolomide for Glioblastoma. N Engl J Med (2005) 352(10):987-96. doi: 10.1056/ NEJMoa043330

39. McCormack A, Dekkers OM, Petersenn S, Popovic V, Trouillas J, Raverot G, et al. Treatment of Aggressive Pituitary Tumours and Carcinomas: Results of a European Society of Endocrinology (ESE) Survey 2016. Eur J Endocrinol (2018) 178(3):265-76. doi: 10.1530/EJE-17-0933

40. Bengtsson D, Schroder HD, Andersen M, Maiter D, Berinder K, Feldt Rasmussen U, et al. Long-Term Outcome and MGMT as a Predictive Marker in 24 Patients With Atypical Pituitary Adenomas and Pituitary Carcinomas Given Treatment With Temozolomide. J Clin Endocrinol Metab (2015) 100(4):1689-98. doi: 10.1210/jc.2014-4350

41. Elbelt U, Schlaffer SM, Buchfelder M, Knappe UJ, Vila G, Micko A, et al. Efficacy of Temozolomide Therapy in Patients With Aggressive Pituitary Adenomas and Carcinomas-A German Survey. J Clin Endocrinol Metab (2020) 105(3):e660-e775. doi: 10.1210/clinem/dgz211

42. Ji Y, Vogel RI, Lou E. Temozolomide Treatment of Pituitary Carcinomas and Atypical Adenomas: Systematic Review of Case Reports. Neurooncol Pract (2016) 3(3):188-95. doi: 10.1093/nop/npv059

43. Lasolle H, Cortet C, Castinetti F, Cloix L, Caron P, Delemer B, et al. Temozolomide Treatment Can Improve Overall Survival in Aggressive Pituitary Tumors and Pituitary Carcinomas. Eur J Endocrinol (2017) 176 (6):769-77. doi: 10.1530/EJE-16-0979

44. Lizzul L, Lombardi G, Barbot M, Ceccato F, Gardiman MP, Regazzo D, et al. Long-Course Temozolomide in Aggressive Pituitary Adenoma: Real-Life Experience in Two Tertiary Care Centers and Review of the Literature. Pituitary (2020) 23(4):359-66. doi: 10.1007/s11102-020-01040-4

45. Zacharia BE, Gulati AP, Bruce JN, Carminucci AS, Wardlaw SL, Siegelin M, et al. High Response Rates and Prolonged Survival in Patients With Corticotroph Pituitary Tumors and Refractory Cushing Disease From Capecitabine and Temozolomide (CAPTEM): A Case Series. Neurosurgery (2014) 74(4):E447-55; discussion E55. doi: 10.1227/NEU.0000000000000251

46. Liu G, Yuan X, Zeng Z, Tunici P, Ng H, Abdulkadir IR, et al. Analysis of Gene Expression and Chemoresistance of CD133+ Cancer Stem Cells in Glioblastoma. Mol Cancer (2006) 5:67. doi: 10.1186/1476-4598-5-67

47. McCormack AI, Wass JA, Grossman AB. Aggressive Pituitary Tumours: The Role of Temozolomide and the Assessment of MGMT Status. Eur J Clin Invest (2011) 41(10):1133-48. doi: 10.1111/j.1365-2362.2011.02520.x

48. Hagen C, Schroeder HD, Hansen S, Andersen M. Temozolomide Treatment of a Pituitary Carcinoma and Two Pituitary Macroadenomas Resistant to Conventional Therapy. Eur J Endocrinol (2009) 161(4):631-7. doi: 10.1530/ EJE-09-0389

49. Annamalai AK, Dean AF, Kandasamy N, Kovacs K, Burton H, Halsall DJ, et al. Temozolomide Responsiveness in Aggressive Corticotroph Tumours: A Case Report and Review of the Literature. Pituitary (2012) 15(3):276-87. doi: 10.1007/s11102-011-0363-7 
50. Losa M, Bogazzi F, Cannavo S, Ceccato F, Curto L, De Marinis L, et al. Temozolomide Therapy in Patients With Aggressive Pituitary Adenomas or Carcinomas. J Neurooncol (2016) 126(3):519-25. doi: 10.1007/s11060-0151991-y

51. Pivonello R, De Leo M, Cozzolino A, Colao A. The Treatment of Cushing's Disease. Endocr Rev (2015) 36(4):385-486. doi: 10.1210/er.2013-1048

52. Ceccato F, Lombardi G, Manara R, Emanuelli E, Denaro L, Milanese L, et al. Temozolomide and Pasireotide Treatment for Aggressive Pituitary Adenoma: Expertise at a Tertiary Care Center. J Neurooncol (2015) 122(1):189-96. doi: 10.1007/s11060-014-1702-0

53. Greenman Y, Stern N. Paradoxical and Atypical Responses to Pasireotide in Aggressive ACTH-Secreting Pituitary Tumors. Pituitary (2016) 19(6):605-11. doi: 10.1007/s11102-016-0755-9

54. Katznelson L. Sustained Improvements in Plasma ACTH and Clinical Status in a Patient With Nelson's Syndrome Treated With Pasireotide LAR, a Multireceptor Somatostatin Analog. J Clin Endocrinol Metab (2013) 98 (5):1803-7. doi: 10.1210/jc.2013-1497

55. Fountas A, Lim ES, Drake WM, Powlson AS, Gurnell M, Martin NM, et al. Outcomes of Patients With Nelson's Syndrome After Primary Treatment: A Multicenter Study From 13 UK Pituitary Centers. J Clin Endocrinol Metab (2020) 105(5):1527-37. doi: 10.1210/clinem/dgz200

56. Daniel E, Debono M, Caunt S, Girio-Fragkoulakis C, Walters SJ, Akker SA, et al. A Prospective Longitudinal Study of Pasireotide in Nelson's Syndrome. Pituitary (2018) 21(3):247-55. doi: 10.1007/s11102-017-0853-3

57. Gatto F, Arvigo M, Ferone D. Somatostatin Receptor Expression and Patients' Response to Targeted Medical Treatment in Pituitary Tumors: Evidences and Controversies. J Endocrinol Invest (2020) 43(11):1543-53. doi: 10.1007/ s40618-020-01335-0

58. Florio T, Thellung S, Arena S, Corsaro A, Spaziante R, Gussoni G, et al. Somatostatin and Its Analog Lanreotide Inhibit the Proliferation of Dispersed Human Non-Functioning Pituitary Adenoma Cells In Vitro. Eur J Endocrinol (1999) 141(4):396-408. doi: 10.1530/eje.0.1410396

59. Fusco A, Giampietro A, Bianchi A, Cimino V, Lugli F, Piacentini S, et al. Treatment With Octreotide LAR in Clinically Non-Functioning Pituitary Adenoma: Results From a Case-Control Study. Pituitary (2012) 15(4):571-8. doi: 10.1007/s11102-011-0370-8

60. Colao A, Di Somma C, Pivonello R, Faggiano A, Lombardi G, Savastano S. Medical Therapy for Clinically Non-Functioning Pituitary Adenomas. Endocr Relat Cancer (2008) 15(4):905-15. doi: 10.1677/ERC-08-0181

61. Zatelli MC, Piccin D, Vignali C, Tagliati F, Ambrosio MR, Bondanelli M, et al. Pasireotide, a Multiple Somatostatin Receptor Subtypes Ligand, Reduces Cell Viability in Non-Functioning Pituitary Adenomas by Inhibiting Vascular Endothelial Growth Factor Secretion. Endocr Relat Cancer (2007) 14(1):91102. doi: 10.1677/ERC-06-0026

62. Flores-Martinez A, Venegas-Moreno E, Dios E, Remon-Ruiz P, Gros-Herguido N, Vazquez-Borrego MC, et al. Quantitative Analysis of Somatostatin and Dopamine Receptors Gene Expression Levels in Non-Functioning Pituitary Tumors and Association With Clinical and Molecular Aggressiveness Features. J Clin Med (2020) 9(9):3052. doi: 10.3390/jcm9093052

63. Fusco A, Gunz G, Jaquet P, Dufour H, Germanetti AL, Culler MD, et al. Somatostatinergic Ligands in Dopamine-Sensitive and -Resistant Prolactinomas. Eur J Endocrinol (2008) 158(5):595-603. doi: 10.1530/EJE-07-0806

64. Sosa-Eroza E, Espinosa E, Ramirez-Renteria C, Mendoza V, Arreola R, Mercado M. Treatment of Multiresistant Prolactinomas With a Combination of Cabergoline and Octreotide LAR. Endocrine (2018) 61 (2):343-8. doi: 10.1007/s12020-018-1638-9

65. Coopmans EC, van Meyel SWF, Pieterman KJ, van Ipenburg JA, Hofland LJ, Donga E, et al. Excellent Response to Pasireotide Therapy in an Aggressive and Dopamine-Resistant Prolactinoma. Eur J Endocrinol (2019) 181(2):K21K7. doi: 10.1530/EJE-19-0279

66. Raverot G, Vasiljevic A, Jouanneau E, Lasolle H. Confirmation of a New Therapeutic Option for Aggressive or Dopamine Agonist-Resistant Prolactin Pituitary Neuroendocrine Tumors. Eur J Endocrinol (2019) 181(2):C1-3. doi: 10.1530/EJE-19-0359

67. Petersenn S. Management of Aggressive Pituitary Tumors - A 2019 Update. Horm Metab Res (2019) 51(12):755-64. doi: 10.1055/a-1060-1883

68. Ilie MD, Lasolle H, Raverot G. Emerging and Novel Treatments for Pituitary Tumors. J Clin Med (2019) 8(8):1107. doi: 10.3390/jcm8081107
69. Cooper O, Vlotides G, Fukuoka H, Greene MI, Melmed S. Expression and Function of ErbB Receptors and Ligands in the Pituitary. Endocr Relat Cancer (2011) 18(6):R197-211. doi: 10.1530/ERC-11-0066

70. Singh B, Carpenter G, Coffey RJ. EGF Receptor Ligands: Recent Advances. F1000Res (2016) 5:2270. doi: 10.12688/f1000research.9025.1

71. Fukuoka H, Cooper O, Ben-Shlomo A, Mamelak A, Ren SG, Bruyette D, et al. EGFR as a Therapeutic Target for Human, Canine, and Mouse ACTHSecreting Pituitary Adenomas. J Clin Invest (2011) 121(12):4712-21. doi: 10.1172/JCI60417

72. Fukuoka H. New Potential Targets for Treatment of Cushing's Disease: Epithelial Growth Factor Receptor and Cyclin-Dependent Kinases. Pituitary (2015) 18(2):274-8. doi: 10.1007/s11102-015-0637-6

73. Ma ZY, Song ZJ, Chen JH, Wang YF, Li SQ, Zhou LF, et al. Recurrent Gain-ofFunction USP8 Mutations in Cushing's Disease. Cell Res (2015) 25(3):306-17. doi: $10.1038 / \mathrm{cr} .2015 .20$

74. Reincke M, Sbiera S, Hayakawa A, Theodoropoulou M, Osswald A, Beuschlein F, et al. Mutations in the Deubiquitinase Gene USP8 Cause Cushing's Disease. Nat Genet (2015) 47(1):31-8. doi: 10.1038/ng.3166

75. Perez-Rivas LG, Theodoropoulou M, Ferrau F, Nusser C, Kawaguchi K, Stratakis CA, et al. The Gene of the Ubiquitin-Specific Protease 8 Is Frequently Mutated in Adenomas Causing Cushing's Disease. J Clin Endocrinol Metab (2015) 100(7):E997-1004. doi: 10.1210/jc.2015-1453

76. Sbiera S, Perez-Rivas LG, Taranets L, Weigand I, Flitsch J, Graf E, et al. Driver Mutations in USP8 Wild-Type Cushing's Disease. Neuro Oncol (2019) 21 (10):1273-83. doi: 10.1093/neuonc/noz109

77. Hayashi K, Inoshita N, Kawaguchi K, Ibrahim Ardisasmita A, Suzuki H, Fukuhara N, et al. The USP8 Mutational Status may Predict Drug Susceptibility in Corticotroph Adenomas of Cushing's Disease. Eur J Endocrinol (2016) 174(2):213-26. doi: 10.1530/EJE-15-0689

78. Faucz FR, Tirosh A, Tatsi C, Berthon A, Hernandez-Ramirez LC, Settas N, et al. Somatic USP8 Gene Mutations Are a Common Cause of Pediatric Cushing Disease. J Clin Endocrinol Metab (2017) 102(8):2836-43. doi: 10.1210/jc.2017-00161

79. Albani A, Perez-Rivas LG, Dimopoulou C, Zopp S, Colon-Bolea P, Roeber S, et al. The USP8 Mutational Status may Predict Long-Term Remission in Patients With Cushing's Disease. Clin Endocrinol (Oxf) (2018). 89:454-8. doi: $10.1111 /$ cen.13802

80. Uzilov AV, Taik P, Cheesman KC, Javanmard P, Ying K, Roehnelt A, et al. USP8 and TP53 Drivers Are Associated With CNV in a Corticotroph Adenoma Cohort Enriched for Aggressive Tumors. J Clin Endocrinol Metab (2021) 106(3):826-42. doi: 10.1210/clinem/dgaa853

81. Liu X, Feng M, Dai C, Bao X, Deng K, Yao Y, et al. Expression of EGFR in Pituitary Corticotroph Adenomas and Its Relationship With Tumor Behavior. Front Endocrinol (Lausanne) (2019) 10:785. doi: 10.3389/ fendo.2019.00785

82. Fukuoka H, Cooper O, Mizutani J, Tong Y, Ren SG, Bannykh S, et al. HER2/ ErbB2 Receptor Signaling in Rat and Human Prolactinoma Cells: Strategy for Targeted Prolactinoma Therapy. Mol Endocrinol (2011) 25(1):92-103. doi: 10.1210/me.2010-0353

83. Vlotides G, Cooper O, Chen YH, Ren SG, Greenman Y, Melmed S. Heregulin Regulates Prolactinoma Gene Expression. Cancer Res (2009) 69(10):4209-16. doi: 10.1158/0008-5472.CAN-08-4934

84. Nose-Alberti V, Mesquita MI, Martin LC, Kayath MJ. AdrenocorticotropinProducing Pituitary Carcinoma With Expression of c-erbB-2 and High PCNA Index: A Comparative Study With Pituitary Adenomas and Normal Pituitary Tissues. Endocr Pathol (1998) 9(1):53-62. doi: 10.1007/BF02739952

85. Cooper O, Mamelak A, Bannykh S, Carmichael J, Bonert V, Lim S, et al. Prolactinoma ErbB Receptor Expression and Targeted Therapy for Aggressive Tumors. Endocrine (2014) 46(2):318-27. doi: 10.1007/s12020-013-0093-x

86. Cooper O, Bonert VS, Rudnick J, Pressman BD, Lo J, Salvatori R, et al. EGFR/ ErbB2-Targeting Lapatinib Therapy for Aggressive Prolactinomas. J Clin Endocrinol Metab (2021) 106(2):e917-e25. doi: 10.1210/clinem/dgaa805

87. Chauvet N, Romano N, Lafont C, Guillou A, Galibert E, Bonnefont X, et al. Complementary Actions of Dopamine D2 Receptor Agonist and Anti-Vegf Therapy on Tumoral Vessel Normalization in a Transgenic Mouse Model. Int J Cancer (2017) 140(9):2150-61. doi: 10.1002/ijc.30628

88. Cristina C, Luque GM, Demarchi G, Lopez Vicchi F, Zubeldia-Brenner L, Perez Millan MI, et al. Angiogenesis in Pituitary Adenomas: Human Studies 
and New Mutant Mouse Models. Int J Endocrinol (2014) 2014:608497. doi: $10.1155 / 2014 / 608497$

89. Osterhage K, Rotermund R, Droste M, Dierlamm J, Saeger W, Petersenn S, et al. Bevacizumab in Aggressive Pituitary Adenomas - Experience With 3 Patients. Exp Clin Endocrinol Diabetes (2021) 129(3):178-85. doi: 10.1055/a1260-3975

90. Ortiz LD, Syro LV, Scheithauer BW, Ersen A, Uribe H, Fadul CE, et al. AntiVEGF Therapy in Pituitary Carcinoma. Pituitary (2012) 15(3):445-9. doi: 10.1007/s11102-011-0346-8

91. Touma W, Hoostal S, Peterson RA, Wiernik A, SantaCruz KS, Lou E. Successful Treatment of Pituitary Carcinoma With Concurrent Radiation, Temozolomide, and Bevacizumab After Resection. J Clin Neurosci (2017) 41:75-7. doi: 10.1016/j.jocn.2017.02.052

92. Rotman LE, Vaughan TB, Hackney JR, Riley KO. Long-Term Survival After Transformation of an Adrenocorticotropic Hormone-Secreting Pituitary Macroadenoma to a Silent Corticotroph Pituitary Carcinoma. World Neurosurg (2019) 122:417-23. doi: 10.1016/j.wneu.2018.11.011

93. Santos-Pinheiro F, Penas-Prado M, Kamiya-Matsuoka C, Waguespack SG, Mahajan A, Brown PD, et al. Treatment and Long-Term Outcomes in Pituitary Carcinoma: A Cohort Study. Eur J Endocrinol (2019) 181(4):397407. doi: 10.1530/EJE-18-0795

94. Zatelli MC, Minoia M, Filieri C, Tagliati F, Buratto M, Ambrosio MR, et al. Effect of Everolimus on Cell Viability in Nonfunctioning Pituitary Adenomas. J Clin Endocrinol Metab (2010) 95(2):968-76. doi: 10.1210/jc.2009-1641

95. Alshaikh OM, Asa SL, Mete O, Ezzat S. An Institutional Experience of Tumor Progression to Pituitary Carcinoma in a 15-Year Cohort of 1055 Consecutive Pituitary Neuroendocrine Tumors. Endocr Pathol (2019) 30(2):118-27. doi: 10.1007/s12022-019-9568-5
96. Donovan LE, Arnal AV, Wang SH, Odia Y. Widely Metastatic Atypical Pituitary Adenoma With mTOR Pathway STK11(F298L) Mutation Treated With Everolimus Therapy. CNS Oncol (2016) 5(4):203-9. doi: 10.2217/cns2016-0011

97. Zhang D, Way JS, Zhang X, Sergey M, Bergsneider M, Wang MB, et al. Effect of Everolimus in Treatment of Aggressive Prolactin-Secreting Pituitary Adenomas. J Clin Endocrinol Metab (2019) 104(6):1929-36. doi: 10.1210/ jc.2018-02461

98. Tatsi C, Stratakis CA. The Genetics of Pituitary Adenomas. J Clin Med (2019) 9(1):30. doi: $10.3390 / \mathrm{jcm} 9010030$

Conflict of Interest: The authors declare that the research was conducted in the absence of any commercial or financial relationships that could be construed as a potential conflict of interest.

Publisher's Note: All claims expressed in this article are solely those of the authors and do not necessarily represent those of their affiliated organizations, or those of the publisher, the editors and the reviewers. Any product that may be evaluated in this article, or claim that may be made by its manufacturer, is not guaranteed or endorsed by the publisher.

Copyright (c) 2021 Cooper, Bonert, Liu and Mamelak. This is an open-access article distributed under the terms of the Creative Commons Attribution License (CC BY). The use, distribution or reproduction in other forums is permitted, provided the original author(s) and the copyright owner(s) are credited and that the original publication in this journal is cited, in accordance with accepted academic practice. No use, distribution or reproduction is permitted which does not comply with these terms. 